\title{
A Coat of \\ Many Colors
}




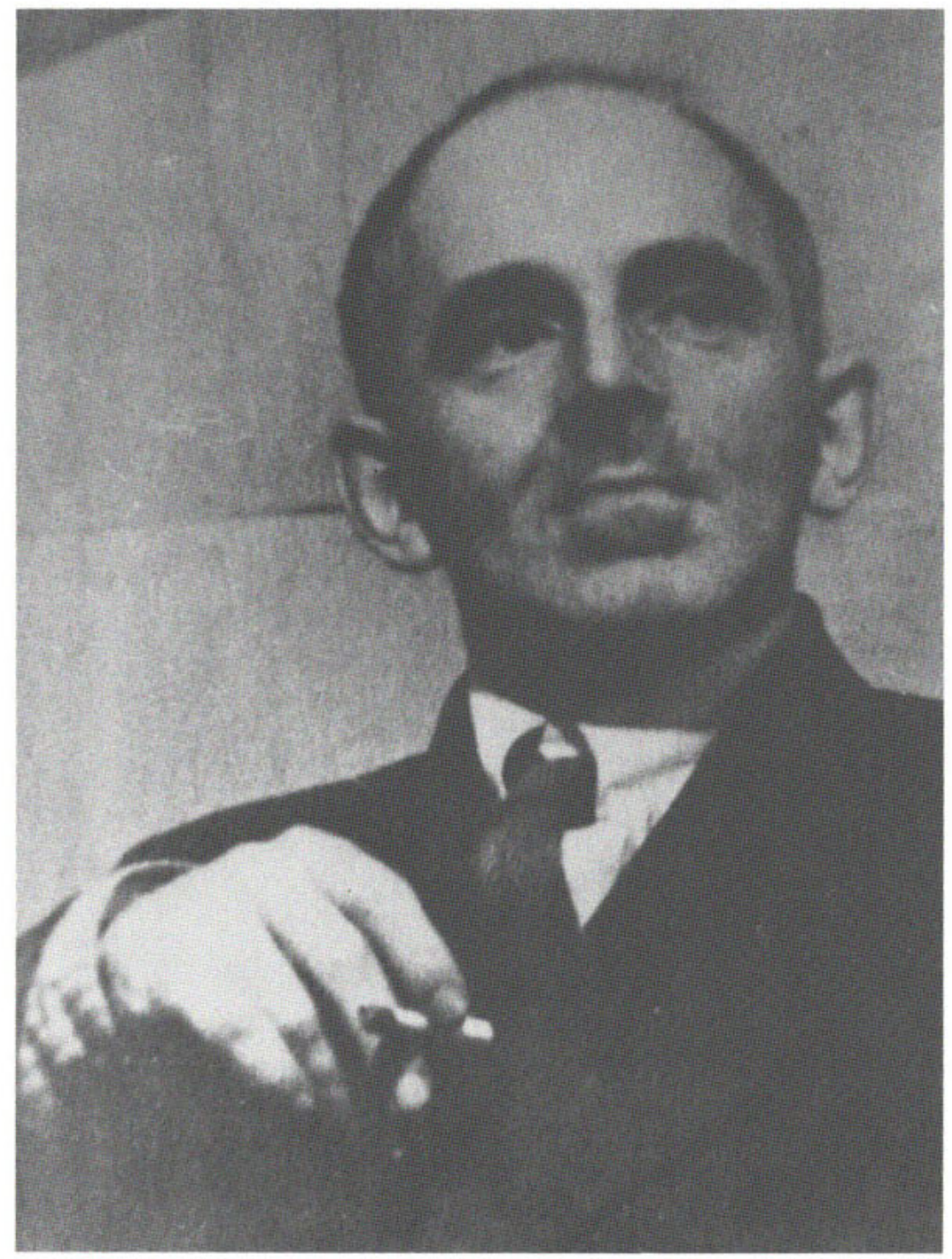

Osip Mandelstam (early 1930s). 


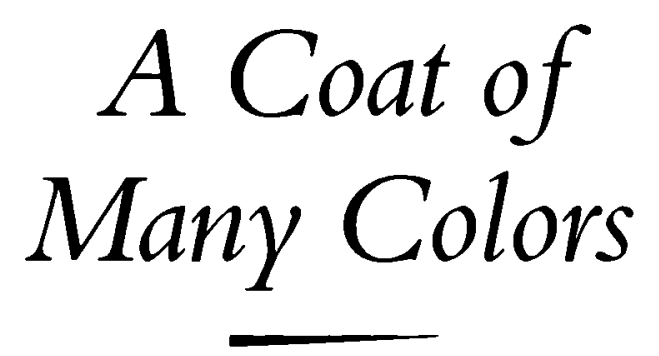

OSIP MANDELSTAM

AND HIS MYTHOLOGIES

OF SELF-PRESENTATION

GREGORY FREIDIN

University of California Press

Berkeley/Los Angeles / London 
University of California Press

Berkeley and Los Angeles, California

University of California Press, Ltd.

London, England

(C) 1987 by

The Regents of the University of California

Printed in the United States of America

$\begin{array}{lllllllll}1 & 2 & 3 & 4 & 5 & 6 & 7 & 8 & 9\end{array}$

Library of Congress Cataloging-in-Publication Data

Freidin, Gregory.

A coat of many colors.

Bibliography: $p$.

Includes index.

1. Mandel'shtam, Osip, 1891-1938-Criticism and

interpretation. I. Title.

PG3476.M355Z64 $1986 \quad 891.71^{\prime} 3 \quad 85-16440$

ISBN 0-520-05438-5 (alk. paper) 
For my parents and in memory of

Ivy Litvinov 
